\title{
Análise em tempo pandêmico de métodos de detecção, prescrições Off-label e uso indiscriminado de medicamentos no Agreste de Pernambuco: Reações Adversas a Medicamentos (RAM's)
}

\author{
Analysis in pandemic time of detection methods, Off-label prescriptions and indiscriminate use of \\ drugs in the Agreste of Pernambuco: Adverse Drug Reactions (ADRs) \\ Análisis del tiempo pandémico de los métodos de detección, prescripciones extraoficiales y uso \\ indiscriminado de medicamentos en la región de Agreste de Pernambuco: Reacciones Adversas a \\ los Medicamentos (RAM)
}

\section{Resumo}

O projeto visa avaliar os métodos de diagnóstico, medicamentos mais prescritos e o uso indiscriminado destes frente a suspeitas ou confirmações do Covid-19 no Agreste Pernambucano, bem como ponderar possíveis RAM's pós o uso desses medicamentos. Com isso, quando comparada a sensibilidade dos três testes disponíveis, o RT-PCR é considerado padrão ouro para o diagnóstico da Covid-19. O uso Off-label de fármacos e a automedicação ganharam enfoque durante a pandemia, podendo ocasionar reações adversas a medicamentos, que são respostas prejudiciais e não-propositais em doses consideradas seguras, quando há esse uso exagerado. Trata-se de um estudo de caráter descritivo, exploratório, com uma abordagem quantitativa e qualitativa por meio de um questionário digital, foi enviado um link de convite para participação na pesquisa e realizado um levantamento de dados constituído por participantes residentes no agreste de Pernambuco, englobando os agrestes Meridional, Central, Setentrional, no período de 20 de Julho a 20 de Setembro de 2021, onde 222 respostas foram consideradas válidas. Os resultados foram organizados em planilhas e ilustrados em gráficos e tabelas, 44 pessoas optaram por fazer o teste RT-PCR, $42,8 \%$ dos entrevistados afirmaram se automedicar, os medicamentos mais prescritos e utilizados por conta própria foram dipirona, vitamina c, azitromicina e ivermectina, observou-se também reações inesperadas, como, hipotensão, hipotermia, enjoo, arritmia, entre outras. Conclui-se que é de suma importância que haja a conscientização e educação em saúde, visando minimizar o ato de automedicação e as consequências oriundas, é necessário também que a população e os profissionais notifiquem em casos de RAM's.

Palavras-chave: COVID-19; Uso Off-label; Automedicação; Reações adversas.

\begin{abstract}
This project aims to analyze the diagnostic methods, the most prescribed drugs and their indiscriminate use in suspected or confirmed cases of Covid-19 in the Agreste Pernambucano, as well as to analyze possible adverse drug reactions (ADR). Thus, when comparing the sensitivity of the three available tests, RT-PCR is considered the gold standard for Covid-19 diagnosis. Off-label use of drugs and self-medication have risen during the pandemic, which may cause adverse drug reactions, harmful and unintended responses at safe doses, due to its overuse. This is a descriptive-exploratory study, with a quantitative and qualitative approach. For the data collection, an invitation link to participate in an online questionnaire was sent to participants residing in the southern, central, and northern parts of the Agreste Pernambucano. The data was collected from July 20 to September 20, 2021 and 222 answers were considered valid. The results were organized in spreadsheets and illustrated in graphs and tables, 44 people chose to
\end{abstract}


do the RT-PCR test, $42.8 \%$ of respondents said they self-medicated, the most prescribed drugs and used on their own were dipyrone, vitamin c, azithromycin and ivermectin, as a consequence of it was also observed unexpected reactions, such as hypotension, hypothermia, nausea, arrhythmia, among others. Therefore, it is of great importance that there should be awareness and education in health, in order to minimize the act of self-medication and its consequences. It is also necessary that the population and professionals notify in cases of ADRs.

Keywords: COVID-19; Off-label use; Self-medication; Adverse reactions.

\section{Resumen}

El proyecto tiene como objetivo evaluar los métodos de diagnóstico, la mayoría de los fármacos prescritos y su uso indiscriminado ante sospechas o confirmaciones de Covid-19 en la región de Agreste Pernambucano, así como considerar posibles RAM tras el uso de estos fármacos. Por lo tanto, al comparar la sensibilidad de las tres pruebas disponibles, la RT-PCR se considera el estándar de oro para el diagnóstico de Covid-19. El uso no autorizado de medicamentos y la automedicación ganó atención durante la pandemia, lo que puede causar reacciones adversas a los medicamentos, que son respuestas dañinas y sin propósito a dosis consideradas seguras, cuando existe un uso excesivo. Se trata de un estudio descriptivo, exploratorio, con enfoque cuantitativo y cualitativo a través de un cuestionario digital, se envió un enlace de invitación a participar de la investigación y se realizó una encuesta de datos conformada por participantes residentes en la región agreste de Pernambuco, abarcando el Sur, Centro, Norte, áreas rurales, en el período del 20 de julio al 20 de septiembre de 2021, donde se consideraron válidas 222 respuestas. Los resultados se organizaron en hojas de cálculo y se ilustraron en gráficos y tablas, 44 personas optaron por realizar la prueba de RT-PCR, el 42,8\% de los encuestados afirmó automedicarse, los fármacos más recetados y de autoconsumo fueron dipirona, vitamina c, azitromicina y ivermectina, también hubo reacciones inesperadas, como hipotensión, hipotermia, náuseas, arritmias, entre otras. Se concluye que es sumamente importante que exista concientización y educación para la salud, con el fin de minimizar el acto de automedicación y las consecuencias resultantes, también es necesario que la población y los profesionales notifiquen en los casos de RAM.

Palabras clave: COVID-19; Uso Off-label; Automedicación; Reacciones adversas.

\section{Introdução}

O SARS-COV-2, popularmente conhecido como Covid-19, segundo a OMS, é o único vírus da família coronavírus com potencial pandêmico. A contaminação ocorre pelo contato do vírus com as vias aéreas e os sintomas podem variar de leves, moderados, a graves, conforme dados disponibilizados pela Fiocruz, a letalidade atualmente encontra-se em 3,0\%, identifica-se uma redução quando comparado ao mês de Abril/2021 que se encontrava em 4,2\%, sendo justificado pelo avanço da vacinação. De acordo com o Ministério da Saúde, existem três possíveis métodos de diagnóstico no Brasil: o teste de biologia molecular, sorologia e testes rápidos. (Brasil, 2021; FIOCRUZ, 2021; OMS, 2020).

Em 2020 a OMS, publicou atualizações nas diretrizes de testes laboratoriais para a doença do novo coronavírus (COVID-19) em casos suspeitos em seres humanos, o documento possui orientações sobre o tipo de amostra que deve ser utilizada, coleta, armazenamento, envio e métodos de diagnóstico, e resultados. Este, traz a informação de que os testes rápidos possuem a sensibilidade mais baixa quando comparados com testes moleculares, já o método de detecção de antígenos, não sendo um modelo de teste rápido, possui uma sensibilidade admissível, e pode ser associada a parâmetros clínicos e epidemiológicos que o paciente apresenta, para uma confirmação mais precisa. (OMS, 2020).

Em virtude da falta de conhecimentos prévios sobre o vírus, segundo a nota informativa $n^{\circ}$ 17/2020- SE/GAB/SE/MS, o tratamento do paciente portador de COVID-19 deve ser baseado na autonomia do médico e na valorização da relação médico-paciente que deve ser a mais próxima possível. (Brasil, 2020).

Contudo, é notável que com as incertezas para o tratamento, as opções terapêuticas disponíveis têm o intuito de amenizar os sintomas, todavia são limitadas e tornam o trâmite crítico, pode-se citar os casos dos medicamentos que tiveram um enrijecimento no controle sobre o tipo de receita exigido para a compra, em razão à alta procura. Como afirma, a RDC N $^{\circ}$ 405, de 22 de julho de 2020:

"Estabelece as medidas de controle para os medicamentos que contenham substâncias constantes do Anexo I desta Resolução, isoladas ou em associação, em virtude da Emergência de Saúde Pública de Importância Internacional (ESPII) relacionada ao novo Coronavírus (SARS-CoV-2)" (ANVISA, 2020, p. 88). 
O consumo de medicamentos vem ganhando enfoque no início a pandemia do Covid- 19, por razão das associações sem aparato científico, como os tão enfatizados "tratamento precoce" e "kit-covid", que são compostos por hidroxicloroquina ou cloroquina, combinadas à azitromicina, à ivermectina e à nitazoxanida, além dos suplementos de zinco e das vitaminas $\mathrm{C} e$ D, tal prática é denominada de prescrição e uso Off-label. Esta, vem recebendo destaque por estar sendo amplamente divulgada em mídias sociais, noticiários, por autoridades públicas e profissionais de saúde. (Melo, et al, 2021).

Quando há uma resposta prejudicial e não-proposital em doses consideradas seguras, entende-se por Reações Adversas a Medicamentos (RAM's) que assim foram definidas, pelo Guia de Segurança dos Medicamentos. De tal modo, é justificado a necessidade de notificá-las, desde o marcante acontecimento da talidomida. São vários os exemplos da importância da notificação, que resultam em melhorias e atualizações das contraindicações, dosagem e RAM's. (OMS/OPAS, 2005).

A facilidade de obter informações, medicamentos e o difícil acesso aos serviços de saúde em tempos pandêmicos, propiciam o aumento da automedicação, que consequentemente, acarretam também a incidência dos casos de bactérias multirresistentes por parte das classes de antimicrobianos. Perante o elucidado, o presente estudo objetiva avaliar os métodos de diagnóstico, medicamentos mais prescritos e o uso indiscriminado destes frente a suspeitas ou confirmações do Covid-19 no Agreste Pernambucano, bem como ponderar possíveis RAM’s pós o uso desses medicamentos.

\section{Metodologia}

Trata-se de um estudo de caráter descritivo, exploratório, com uma abordagem quantitativa e qualitativa. Apresenta-se como objetivo, analisar por meio de questionário online os métodos de detecção, as prescrições, assim como o uso indiscriminado de medicamentos frente a suspeitas ou confirmações do Covid-19, no Agreste Pernambucano, e identificar as possíveis RAM's oriundas do uso Off-label.

O levantamento dos dados foi constituído mediante à respostas obtidas pelos participantes residentes nas cidades que compõem o Agreste de Pernambuco, englobando os agrestes Meridional, Central, Setentrional.

A população amostral foi composta por pessoas com suspeita ou confirmação de COVID-19 que necessitaram ou não de assistência médica durante todo o período pandêmico. 254 indivíduos participaram do questionário, mas apenas 222 foram considerados válidos para o estudo em questão, 32 respostas foram excluídas pois estavam fora dos requisitos impostos, visto que não residiam no raio da pesquisa.

Ter utilizado medicamentos para tratamento e prevenção de covid-19, de forma autônoma ou por meio de prescrição, ter acima de 18 anos e residir no Agreste Pernambucano, foram os nossos critérios de inclusão. Os critérios de exclusão usados foram, pessoas menores de 18 anos, que discordem do Termo de Consentimento Livre e Esclarecido (TCLE) ou que não residirem na localização requerida.

O projeto foi aprovado pelo Comitê de Ética e Pesquisa (CEP) do Centro Universitário do Vale do Ipojuca UNIFAVIP WYDEN sob o parecer de número 4.837.924.

O questionário ficou no ar de 20 de julho de 2021 a 20 de setembro de 2021, onde foi divulgado via link juntamente com um convite para participação, nas principais redes sociais, como, Instagram e Whatsapp, para a coleta de dados sobre medicamentos, sintomas, exames, e possíveis RAM's. O questionário conteve doze questões, estas variando entre objetivas e subjetivas em formato digital, por meio da plataforma Google Forms.

Vale salientar que todos os participantes tiveram direito de escolha e poderiam abandonar a qualquer momento a pesquisa, sem mais constrangimentos e garantindo a integridade do mesmo.

Após o encerramento do período de acesso ao questionário no Google Forms, organizou-se as informações no Google Planilhas, realizando um levantamento quantitativo e qualitativo. Utilizando cálculos por porcentagens e medidas de tendência 
central (moda, média e mediana) para análise de dados, apresentando os resultados por meio de tabelas e gráficos, evidenciando e justificando o tema defendido.

\section{Resultados e Discussão}

Ao filtrar as respostas, foram validadas apenas 222, a maioria obtida foi do sexo feminino totalizando $72,1 \%$ destas, mais precisamente, 160 pessoas. $68 \%$ são da faixa etária de 18 a 25 anos, sendo considerada a prevalência, 23,4\% são de 26 a 39 anos, $7,2 \%$ de 40 a 60 anos e $1,4 \%+61$ anos.

Levando em conta que o Agreste Pernambucano é composto por 71 cidades, fracionado em Agreste central, meridional e setentrional, atingimos 27 municípios, compreendendo a região. Como ilustrado no Gráfico 1 , as cidades que mais obteve-se respostas foram Garanhuns, Belo Jardim e Caruaru, com 31,08\%, 28,83\% e 13,06\%, respectivamente. Segundo dados da Secretaria Estadual de Saúde de Pernambuco, esses três municípios acumulam um total de 54.104 casos confirmados até o dia 20 de setembro de 2021. (Brasil, 2021).

Gráfico 1. Quantitativo de pessoas que responderam ao questionário por cidade.

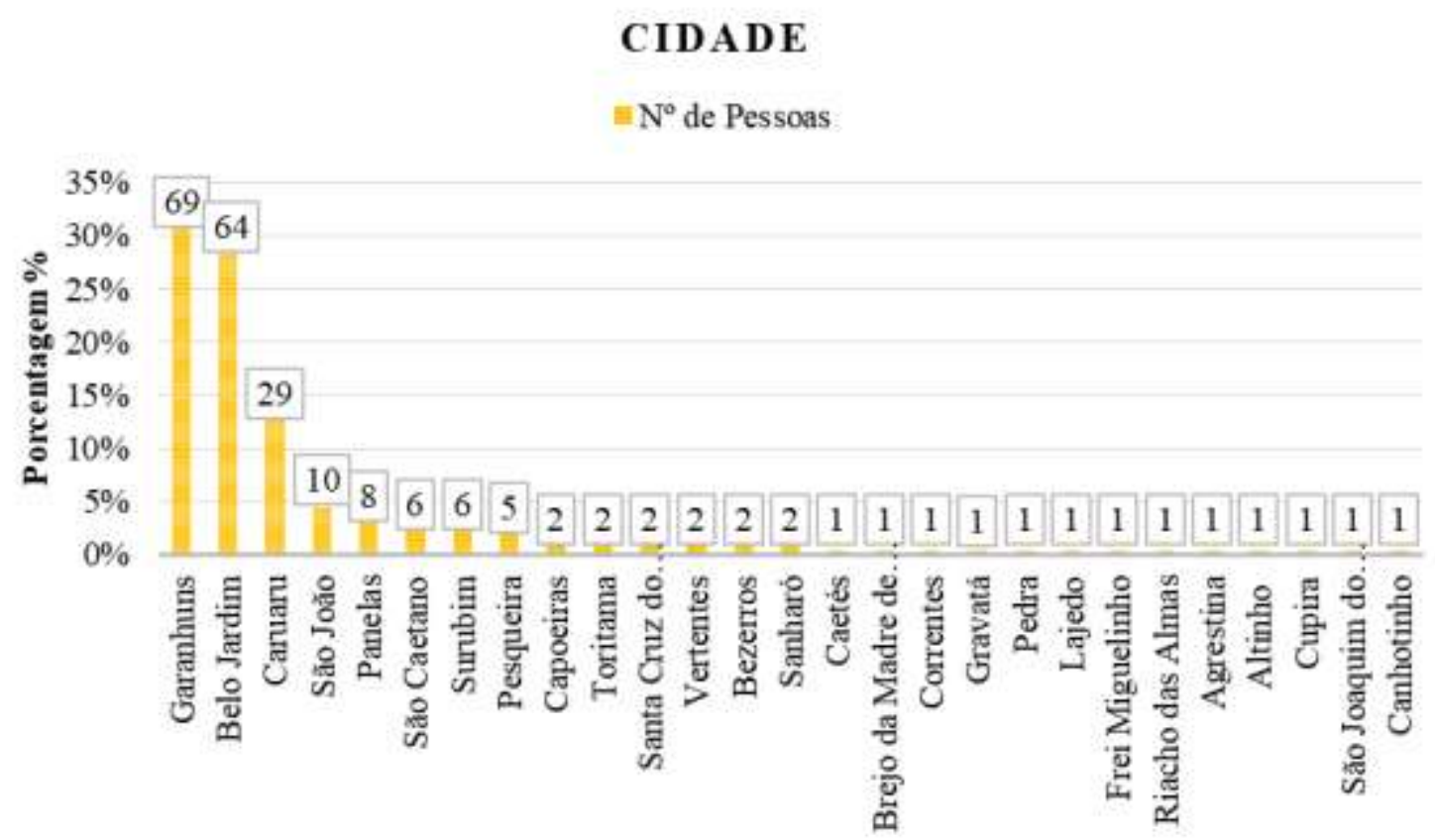

Fonte: Autores.

Quando perguntados sobre a positividade da contaminação por COVID-19, 41,4\% dos participantes afirmaram ter testado positivo, $37,8 \%$ não foram contaminadas, e 20,7\% das pessoas ainda possuem dúvida, visto que para alguns é manifestado de forma assintomática e outros não chegaram a realizar teste, como abordado no Gráfico 2. 
Gráfico 2. Total de narticinantes aue foram infectados nelo COVID-19.

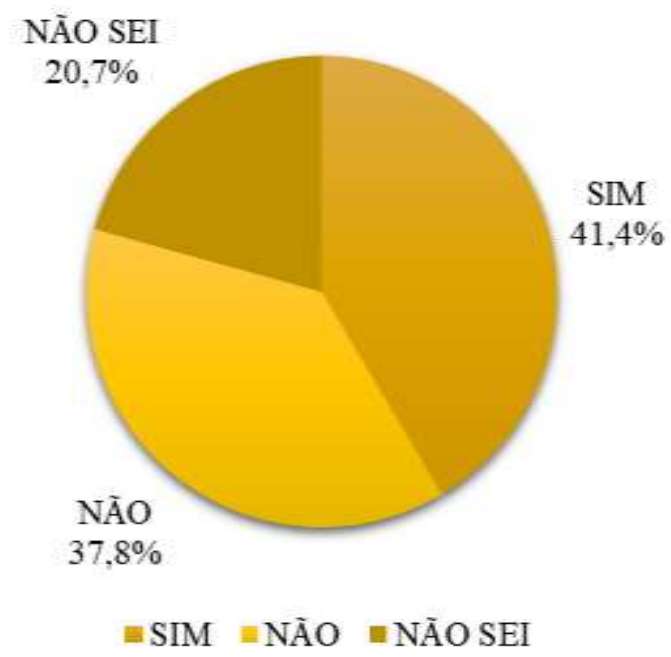

Fonte: Autores.

Sobre os testes feitos, como expostos no Gráfico 3, 32 pessoas realizaram o teste sorológico, 39 realizaram teste rápido e 44 optaram por fazer o RT-PCR. De acordo com Lima et al (2020 apud BRASIL, 2020, p. 3) as testagens são imprescindíveis no enfrentamento do SARS-CoV-2, uma vez que o diagnóstico é apontado como principal aliado para a tomada de medidas profiláticas contra a disseminação do vírus, como também, a inicialização do tratamento e/ou condutas, a depender do estado de saúde em que o paciente se encontra.

Anticorpos contra os antígenos do SARS-CoV-2 IgG, IgM e IgA e totais podem ser detectados em sangue total, soro ou plasma por testes convencionais (ensaios imunoenzimáticos ou quimioluminescência) ou testes rápidos imunocromatográficos. A acurácia dos testes sorológicos varia por metodologia, antígeno empregado e momento da coleta (idealmente após $10^{\circ}$ dia para $\operatorname{IgM}$, IgA e anticorpos totais e, após $15^{\circ}$ dia, para $\operatorname{IgG}$ ). O teste padrão ouro para o diagnóstico da COVID-19 é o RT-PCR. (Dias, et al, 2020).

Gráfico 3. Testes realizados para detecção do vírus.

\section{TESTES REALIZADOS}

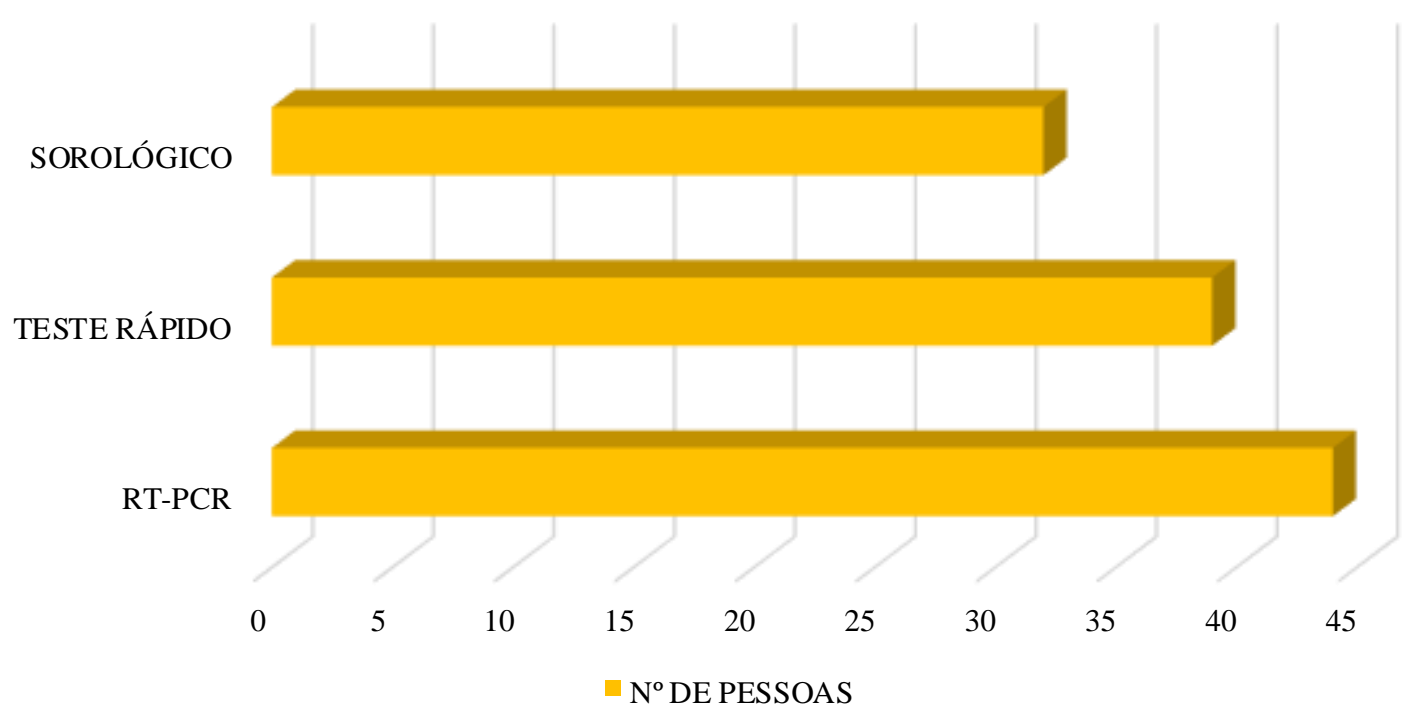

Fonte: Autores. 
No Gráfico 4, é notório que os sintomas mais citados pelos indivíduos foram cansaço, dores e/ou desconfortos, seguidos também de perda de paladar e/ou olfato. Vale salientar que os mesmos alegaram um conjunto dos sintomas. Informações essas, que podem ser classificadas como casos leves, "caracterizado a partir da presença de sintomas não específicos, como tosse, dor de garganta ou coriza, seguido ou não de anosmia, ageusia, diarreia, dor abdominal, febre, calafrios, mialgia, fadiga e/ou cefaleia”. (Brasil, 2021).

Gráfico 4. Sintomas abordados pelos participantes.

\section{SINTOMAS}

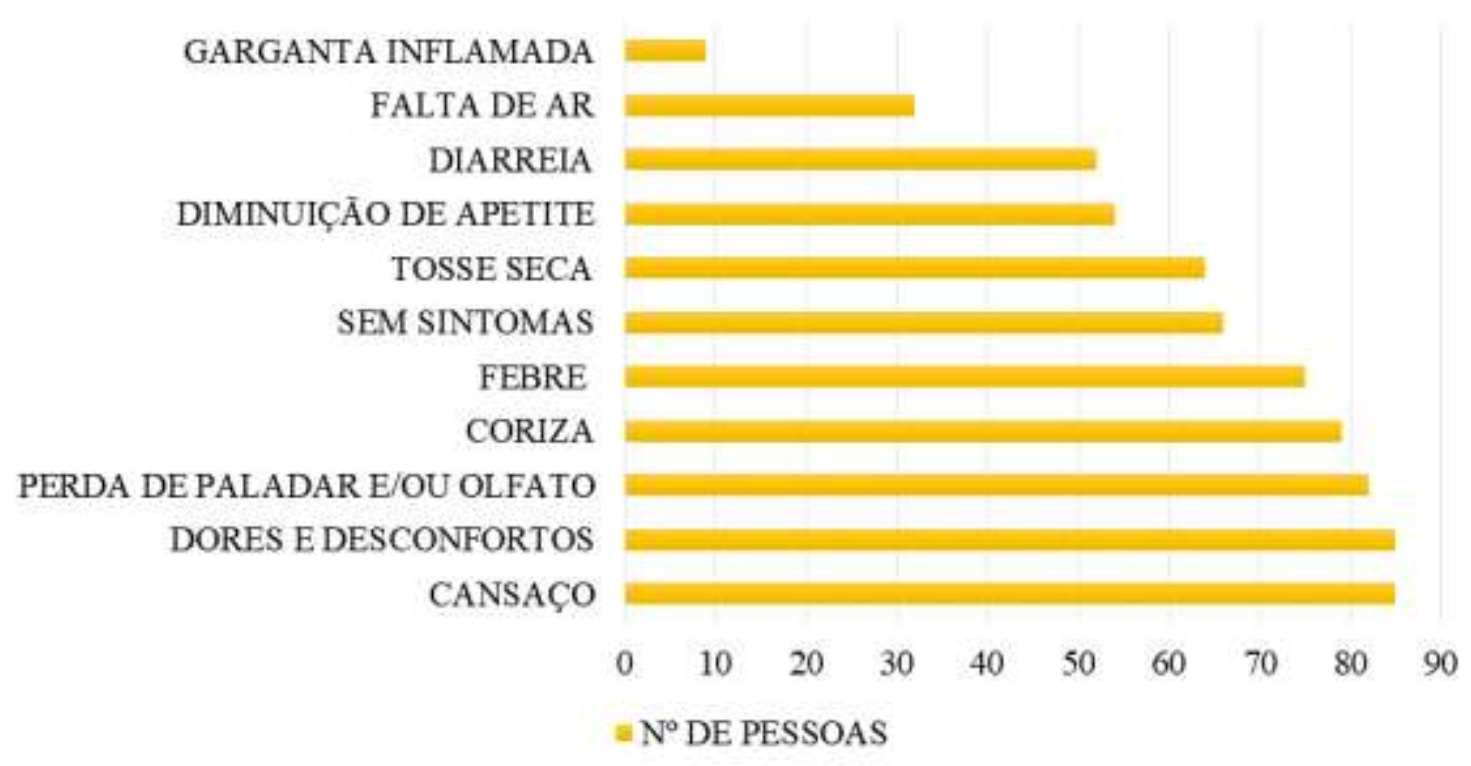

Fonte: Autores.

Durante o período de pandemia, 68,9\% não necessitaram de acompanhamento médico ou internação, 31,1\% fizeram consulta médica e/ou foram internadas, em busca de um tratamento eficaz, entre os meses que mais houveram prescrições em 2020 foram mencionados Junho a Setembro, já em 2021, o pico de prescrições ocorreu no mês de Maio, segundo o questionário, como exibido no Gráfico 5.

Gráfico 5. Percentual de integrantes que foram ao médico ou precisaram de internação em tempos pandêmicos.

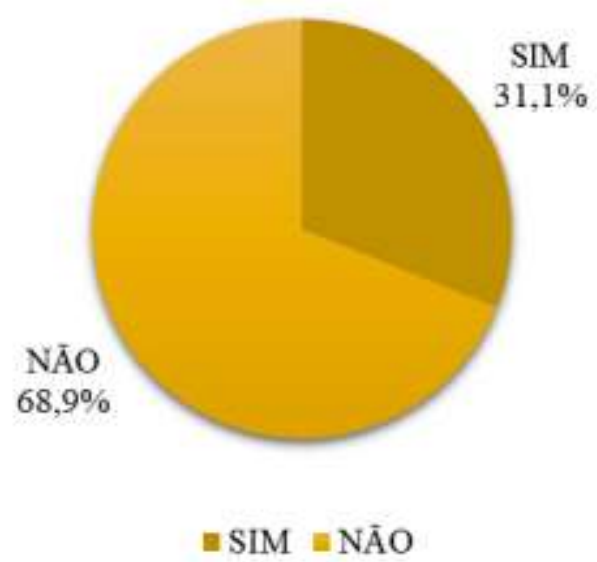

Fonte: Autores. 
Como explícito nas respostas e Tabela 1, os medicamentos que mais foram prescritos, foram Vitamina C, Dipirona, Azitromicina e Ivermectina. Vale destacar que "vários estudos foram realizados em todo o mundo e publicados em revistas científicas renomadas, que, após analisarem a utilização dos medicamentos como alternativa para o tratamento da Covid-19, atestaram sua ineficácia, bem como alertaram para a produção de efeitos colaterais decorrentes da sua utilização". (Vernier, 2021).

Tabela 1. Medicamentos mais prescritos.

\begin{tabular}{l|r}
\hline \multicolumn{1}{|c|}{ MEDICAMENTOS } & $N^{N}$ DE PESSOAS \\
\hline VITAMINA C & 43 \\
\hline DIPIRONA & 41 \\
\hline AZITROMICINA & 38 \\
\hline IVERMECTINA & 26 \\
\hline VITAMINA D & 16 \\
\hline ZINCO QUELATO & 7 \\
\hline DEXAMETASONA & 6 \\
\hline
\end{tabular}

Fonte: Autores.

O Gráfico 6 quantifica os indivíduos que não só realizaram exames, como também observaram alterações. Das 19 pessoas que realizam exames durante o período, 6 apresentaram alterações no hemograma, relatando alterações nos leucócitos. Em um estudo realizado por Carelli et al (2020) os autores supõem que "os níveis de leucócitos na admissão do paciente com COVID-19 podem indicar a gravidade da doença e que acompanhar os níveis de hemoglobina, LDH e D-dímero durante a internação do paciente possa ser importante para avaliar a progressão da doença. Outros estudos são necessários para determinar quais parâmetros laboratoriais terão maior capacidade de predizer a resposta ao tratamento e o desfecho clínico de pacientes com COVID-19.”

Gráfico 6. Relação de participantes que realizaram exames e houveram alterações.

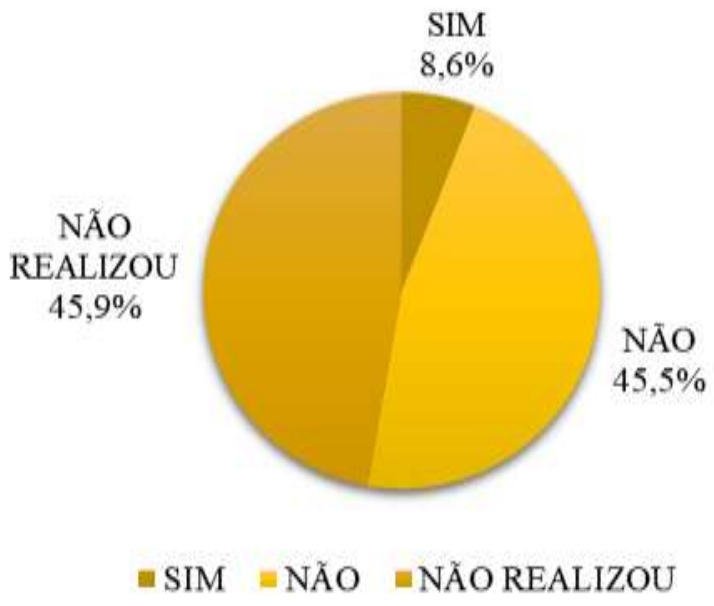

Fonte: Autores.

Ao longo desse período, 42,8\% responderam ter se automedicado e 57,2\% negaram o ato, conforme o Gráfico 7. Para Guimarães (2020 apud Luccheta; Mastroianni 2020, p. 2) "no desejo de encontrar uma solução rápida e fácil para a doença e 
influenciados por ideologias, muitos indivíduos começaram a realizar a prática de automedicação. Foi observado aumento nas pesquisas via internet pelos medicamentos e relatados escassez dos fármacos, mortes e intoxicações."

Gráfico 7. Proporção de respostas sobre automedicação.

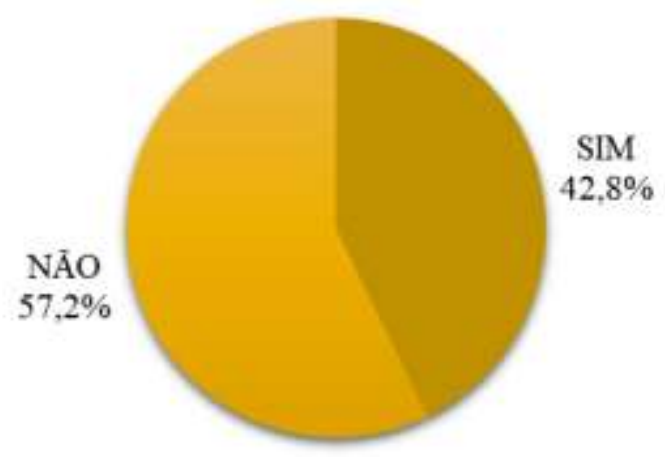

$=\mathrm{SIM}=\mathrm{NA} O$

Fonte: Autores.

De acordo com os entrevistados que se automedicaram, as classes mais mencionadas foram analgésicos, como dipirona e paracetamol; antibióticos, azitromicina e amoxicilina; anti-inflamatório, nimesulida e ibuprofeno; suplemento vitamínico, vitamina C; e antiparasitário, ivermectina, evidenciado no Gráfico 8. A ausência de um tratamento específico respaldado em dados científicos e pesquisas clínicas levou a população brasileira a procurar métodos de autocuidado por conta própria, como a automedicação. As taxas de automedicação encontradas [...] em cenário de pandemia, foram maiores do que as encontradas em outros trabalhos previamente reportados. (Pitta, et al, 2021).

Gráfico 8. Medicamentos mais descritos em automedicacão.

\section{MEDICAMENTOS UTILIZADOS}

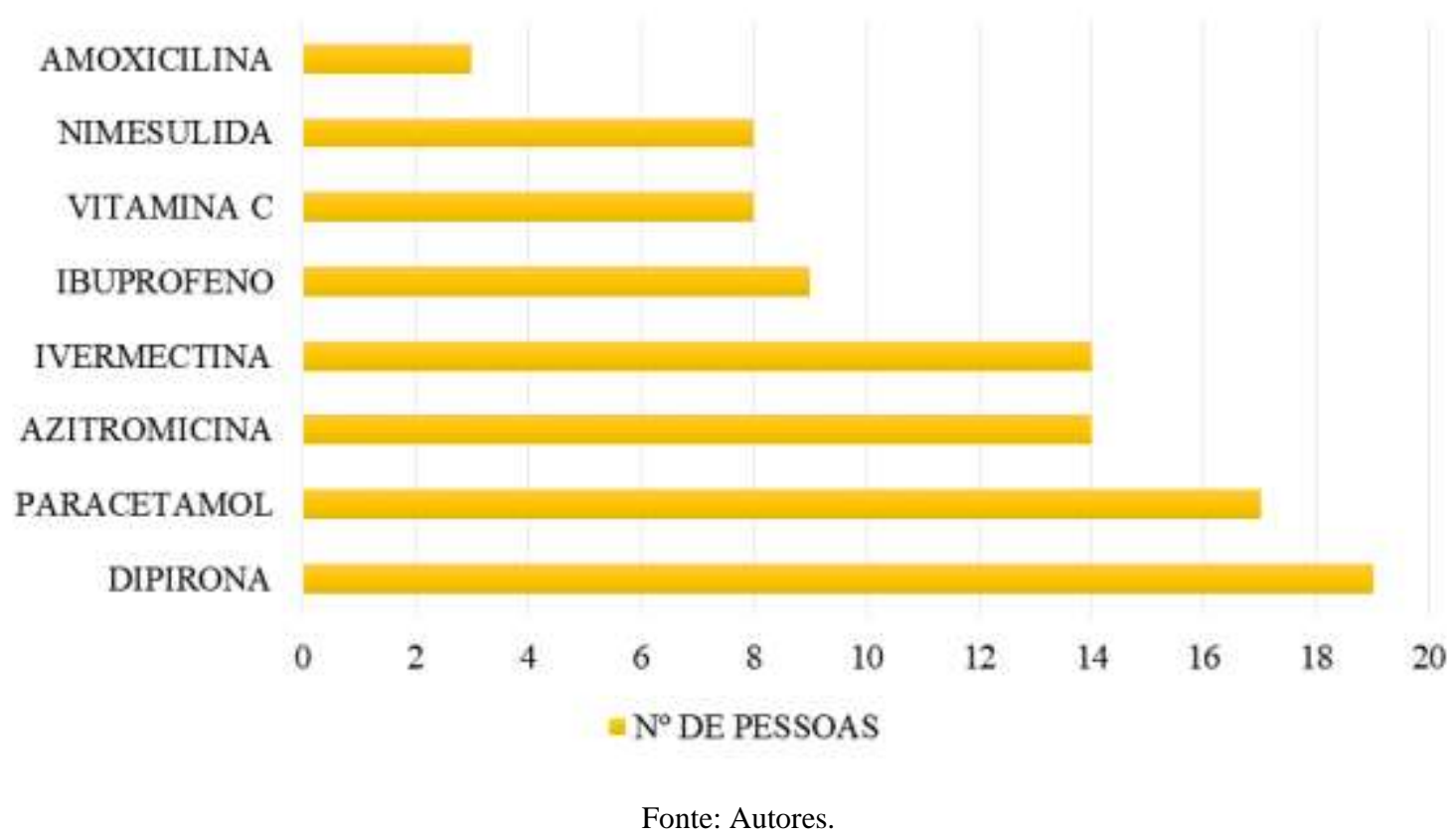


Por não haver opções terapêuticas comprovadas, algumas figuras políticas levaram alguns medicamentos ao topo da mídia, o que poderia induzir a população a fazer o uso. Diante disso, foi questionado sobre a influência, cerca de $14,4 \%$ das respostas se mostraram inspiradas por tais representantes, 11,7\% apresentaram dúvida, 1,4\% não souberam responder e 72,5\% se mostraram não influenciável, expresso no Gráfico 9. Um estudo semelhante realizado por Pitta, et al (2021), conclui que há uma grande influência de familiares, amigos, médicos colegas e as mídias digitais têm na tomada de decisões das pessoas, sendo importante, neste sentido, o desenvolvimento de pensamento crítico, para que a tomada de decisão seja baseada em evidências científicas, e não em opiniões pessoais ou posicionamentos políticos.

Gráfico 9. Influência do uso de medicamentos através de figuras públicas.

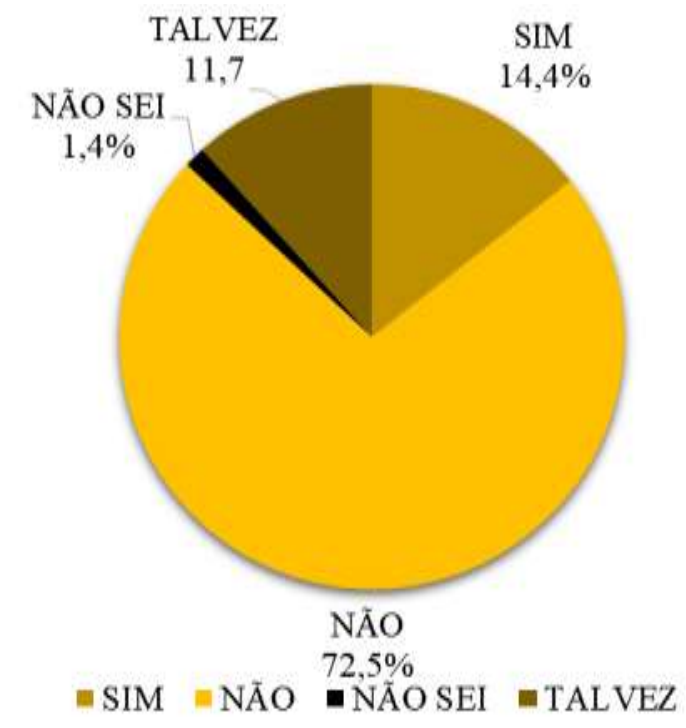

Fonte: Autores.

Após o uso dos fármacos, 5\% responderam sentir uma possível reação adversa ao mesmo, 2,7\% permaneceram em dúvida, 5,9\% não sabiam afirmar e 86,5\% não notaram reações adversas, demonstrado no Gráfico 10. Dentre as reações adversas, foram descritas: hipotermia, hipotensão, enjoo, dor de cabeça, insônia, arritmia, febre, alucinações, diarreia, entre outras. De acordo com informações obtidas em uma base de dados da OMS, houve um grande aumento de notificações de reações adversas de alguns medicamentos quando comparado os anos de 2019, antes da pandemia, e 2020-2021. (VigiAcess, 2021).

Conciliando com os fármacos mais utilizados no presente estudo, foram reunidos subsídios sobre estes, para a Ivermectina, em 2019 constava apenas 543 notificações em escala mundial, já 2020-2021, totalizaram 2.524 casos. Para a Azitromicina, no ano de 2019, 7.581 episódios de RAM's foram apontados, esse número ascendeu para 18.558. Nos eventos envolvendo Dipirona e Paracetamol, 2.034 e 22.699 em 2019, respectivamente, elevando-se para 4.442 e 25.275 em 2020 2021, de modo respectivo. (VigiAcess, 2021). 
Gráfico 10. Possíveis RAM's.

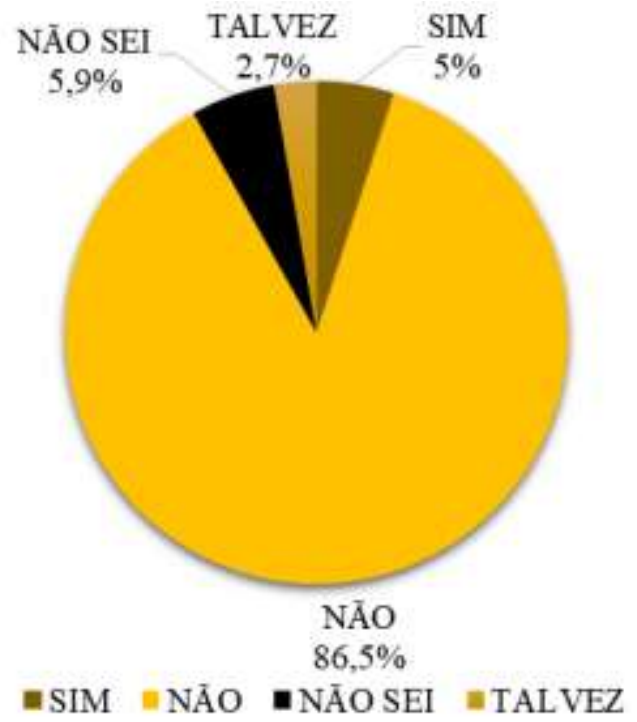

Fonte: Autores.

\section{Considerações Finais}

Envolvido no contexto de que a realização dos métodos de diagnóstico é imprescindível para uma melhor especificidade no tratamento, cerca de 115 pessoas do total de entrevistados realizaram testes para a confirmação do Covid-19, 38,2\% optou pelo RT-PCR, 33,9\% pelo teste rápido e 27,8\% pelo sorológico. Observa-se a prevalência do RT-PCR, sendo respaldado que ele traz consigo uma melhor confiabilidade, devido a sua maior sensibilidade.

A partir da análise do questionário, nota-se que os medicamentos mais prescritos foram as vitaminas $\mathrm{C}$ e $\mathrm{D}$, dipirona, azitromicina e ivermectina, reforçando que todos esses tiveram o uso de forma Off-label. Em contrapartida à prescrição, o emprego de formas farmacêuticas sem orientação médica foi apontado em 42,8\% das respostas, narrando-se os seguintes fármacos: dipirona, paracetamol, azitromicina, ivermectina e vitamina C, nessa ordem de importância.

Dado os fatos expostos, acredita-se que a utilização em excesso das classes vitamínicas, leva a ideia de que apenas reforçam a imunidade e que por serem suplementos vitamínicos, não acarretam mal nenhum. Do mesmo modo, os analgésicos mais citados, são os predominantes para tratamento de dores e/ou desconfortos causados pela suspeita do vírus em questão. Dessa mesma maneira, a azitromicina se destaca em meio aos antibióticos, levando a possíveis ocorrências de resistência microbianas, ocasionando uma piora de caso clínico e elevando esse problema de saúde pública a nível mundial. Nesse seguimento, o antiparasitário ivermectina, pode ter sido influenciado de acordo com os pronunciamentos de figuras públicas, que de certa forma incentivaram o uso deste, que compõe o "kit-covid", mesmo não tendo aparato cientifico.

A prática da autoadministração de fármacos demasiadamente tendem a originar eventos inesperados, tais como, hipotermia, hipotensão, enjoo, dor de cabeça, insônia, arritmia, alucinações, entre outros, que foram descritos no questionário, tendo em vista que todos os medicamentos têm um percentual de provocar danos à saúde, que muitas vezes, são irreversíveis.

Conclui-se que é de suma importância que haja a conscientização e educação em saúde, visando minimizar o ato de automedicação e as consequências oriundas. O que auxilia também, é a integração da população e dos profissionais em nutrir plataformas que tem a finalidade de reunir notificações em busca de monitorar a frequência em que ocorrem RAM's. 
A pesquisa desperta a atenção e sensibilização quanto ao tema e irá servir como embasamento para futuros estudos semelhantes. Para continuidade e aprofundamento sobre o assunto serão necessários, estudos complementares no pós pandemia que abordem os mesmos aspectos, para então tentar identificar consequências a longo prazo.

\section{Agradecimentos}

Agradecemos a todos que direta ou indiretamente contribuíram para a construção e sucesso do artigo.

\section{Referências}

Agência Nacional de Vigilância Sanitária. (2019). VigiMed: Sistema de notificação de eventos adversos no uso de medicamentos no uso de medicamentos https://www.gov.br/anvisa/pt-br/assuntos/fiscalizacao-e-monitoramento/notificacoes/vigimed/arquivos/vigimed-perguntas-e-respostas.pdf/view

Agência Nacional de Vigilância Sanitária. (2021). Notificação de eventos adversos a medicamentos https://www.gov.br/anvisa/pt-br/assuntos/noticiasanvisa/2021/anvisa-alerta-para-riscos-do-uso-indiscriminado-de medicamentos/20213103_comunicado_ggmon_003_2021.pdf

Barbosa, J. D. C. S., \& Resende, F. A. (2018). Perfil do uso indiscriminado de medicamentos na cidade de Cordisburgo-MG. Revista Brasileira de Ciências da Vida, 6(3).

Cabral, F. F., Pereira, M. B., Borges, K. D. M., de Brito Passos, A. C., Francelino, E. V., Monteiro, M. P., \& Arrais, P. S. D. (2020). Eventos Adversos A Medicamentos No Tratamento Da Covid-19 No Ceará: Adverse Events To Medicines In The Treatment Of COVID-19 In Ceará. Cadernos ESP-Revista Científica da Escola de Saúde Pública do Ceará, 14(1), 30-37.

Carelli, G. Z., de Brito Carvalho, B. R., Dal Molin, B., Duarte, C. R., Martins, G. K. F., Wendt, G. W., \& Ferreto, L. E. D. (2020). Alterações laboratoriais em pacientes com COVID-19. Research, Society and Development, 9(12), e30191211115-e30191211115.

Centro de Vigilância Sanitária. (2021). Farmacovigilância Perguntas Frequentes http://www.cvs.saude.sp.gov.br/faq.asp?te_codigo=22

Conselho Federal de Farmácia. (2021). CFF alerta população sobre o uso de medicamentos https://www.cff.org.br/noticia.php?id=6278\&titulo=CFF+ alerta+popula\%C3\%A7\%C3\%A3o+sobre+o+uso+de+medicamentos

Conselho Federal de Farmácia. (2020). Guia farmacoterapêutico para o tratamento específico da Covid-19 em pacientes graves https://www.cff.org.br/userfiles/Guia\%20farmacoterapeutico.pdf

da Rocha Pitta, M. G., de Lima, L. P., de Carvalho, J. S., Teixeira, D. R. C., de Sousa Nunes, T. R., da Silva Moura, J. A., \& da Rocha Pitta, I. (2021). Análise do perfil de automedicação em tempos de COVID-19 no Brasil. Research, Society and Development, 10(11), e28101119296-e28101119296.

Estrela, C. (2018). Metodologia Científica: Ciência, Ensino, Pesquisa. Editora Artes Médicas.

Fundação Oswaldo Cruz. (2020). Resistência a antibióticos e COVID-19 https://www.bio.fiocruz.br/index.php/br/noticias/1823-modernidadee\%20sustentabili\%20dade-no-centro-tecnologico-de-plataformas-vegetais

Fundação Oswaldo Cruz. (2021). Boletim reforça relevância de passaporte de vacinas na retomada de atividades https://portal.fiocruz.br/noticias/boletimreforca-relevancia-de-passaporte-de-vacinas-na-retomada-de-atividades

Governo Federal Do Brasil. (2020). OMS classifica coronavírus como pandemia https://www.gov.br/pt-br/noticias/saude-e-vigilancia-sanitaria/2020/03/omsclassifica-coronavirus-como-pandemia

Governo Federal Do Brasil. (2020). Resolução De Diretoria Colegiada - RDC No 405, De 22 De Julho De 2020 https://www.in.gov.br/en/web/dou/-/resolucaode-diretoria-colegiada-rdc-n-405-de-22-de-julho-de-2020-268192342

Manzato, A. J., \& Santos, A. B. (2012). A elaboração de questionários na pesquisa quantitativa. Departamento de Ciência de Computação e EstatísticaIBILCE-UNESP, 1-17.

Ministério da Economia. (2021). Observatório de Tecnologias Relacionadas ao Covid-19 https://www.gov.br/inpi/pt-br/servicos/patentes/tecnologias-paracovid-19/Medicamentos

Ministério da Saúde. (2020). Orientações do Ministério da Saúde para manuseio medicamentoso precoce de pacientes com diagnóstico da Covid-19 https://f82dccd2-5978-4130-b790-c3b4cbccdf18.filesusr.com/ugd/86f521_329be9dffa7149208eaf01d22e2bfaeb.pdf

Ministério da Saúde. (2020). Coronavírus Perguntas e Respostas https://www.gov.br/anvisa/pt-br/acessoainformacao/perguntasfrequentes/paf/coronavirus

Ministério da Saúde. (2020). Boletim Extraordinario 2021-MARCO-03 https://portal.fiocruz.br/sites/portal.fiocruz.br/files /documentos/boletim_extraordina rio_2021-abril-06-red_2.pdf

Ministério da Saúde. (2021). Sintomas https://www.gov.br/saude/pt-br/coronavirus/sintomas

Melo, J. R. R., Duarte, E. C., Moraes, M. V. D., Fleck, K., \& Arrais, P. S. D. (2021). Automedicação e uso indiscriminado de medicamentos durante a pandemia da COVID-19. Cadernos de Saúde Pública, 37, e00053221.

Melo, J. R. R., Duarte, E. C., Moraes, M. V. D., Fleck, K., Silva, A. S. D. N., \& Arrais, P. S. D. (2021). Reações adversas a medicamentos em pacientes com COVID-19 no Brasil: análise das notificações espontâneas do sistema de farmacovigilância brasileiro. Cadernos de Saúde Pública, 37 , e00245820. 
Research, Society and Development, v. 10, n. 14, e311101422193, 2021

(CC BY 4.0) | ISSN 2525-3409 | DOI: http://dx.doi.org/10.33448/rsd-v10i14.22193

Mota, D. M., Vigo, Á., \& Kuchenbecker, R. D. S. (2019). Reações adversas a medicamentos no sistema de farmacovigilância do Brasil, 2008 a 2013 : estudo descritivo. Cadernos de Saúde Pública, 35, e00148818.

do Nascime, A. T. M. B., de Oliveira, D. D. C., de Oliveira Barroso, N., Viana, R. O., Nerys, S. L. D. N. P., dos Reis Sena, S. R., \& Fontes, J. L. F. (2021). Os riscos do uso irracional de medicamentos durante a pandemia covid-19. Mostra de Inovação e Tecnologia São Lucas (2763-5953), 1(2).

Organização Mundial Da Saúde. (2005). Segurança dos medicamentos: um guia para detectar e notificar reações adversas a medicamentos. Por que os profissionais de saúde precisam entrar em ação https://www.paho.org/bra/index.php?option=com_docman\&view=download\&alias=787-seguranca-dosmedicamentos-um-guia-para-detectar-e-notificar-reacoes-adversas-a-medicamentos-7\&category_slug=vigilancia-sanitaria-959\&Itemid=965

Rampazzo Soares, F. (2020). Prescrição de medicamentos? off-label? no direito brasileiro: responsabilidade médica e desafios em tempos de COVID-19.

Secretária de Saúde do Estado de Pernambuco. (2021). Boletim COVID-19 https://drive.google.com/file/d/1VSQVIkgeFxzD8qcqMusGwFINJpn_QLAS/view Severino, A. J. (2018). Metodologia do trabalho científico. Cortez.

Soares, F. R., \& Dadalto, L. (2020). Responsabilidade médica e prescrição off-label de medicamentos no tratamento da COVID-19. Revista IBERC, 3(2), 1-22.

Vernier, J. S. A Prescrição Medicamentosa Off-Label Para O Tratamento Da COVID-19 E A Responsabilidade Médica.

World Health Organization. (2020). Target product profiles for needed antibacterial agents: enteric fever, gonorrhoea, neonatal sepsis, urinary tract infections and meeting report.

World Health Organization. (2020). Laboratory testing for coronavirus disease (COVID-19) in suspected human cases: interim guidance, 19 March 2020 (No. WHO/COVID-19/laboratory/2020.5). World Health Organization. 